\title{
Digital mobile advertising: A Pitching research letter
}

\author{
Haroon Iqbal Maseeh ${ }^{\mathrm{a}, 11}$ \\ ${ }^{a}$ Griffith Business School, Griffith University, Australia
}

\begin{abstract}
This pitch research letter applies the pitching template developed by Faff $(2015 ; 2019)$ to an academic project titled "Impact of digital mobile advertising on customers' purchase intention; mediating role of customer motivation and customer perception". This PRL forms a framework for a research project which helps the pitcher identify core elements of research. This PRL consists of introduction of the pitching letter, followed by brief commentary on pitching exercise and personal reflection of the pitcher on this exercise.
\end{abstract}

Keywords: Digital mobile advertising, purchase intention, mobile marketing, customer motivation, customer perception, pitching research

\section{JEL codes: M31, M37}

\section{Introduction}

I am currently a $\mathrm{PhD}$ candidate at the Department of Marketing Griffith Business School Griffith University. My area of research is digital advertising. I completed by MBA in marketing from University of the Punjab Gujranwala Campus Pakistan. The purpose of this pitching research letter is to apply the pitch template developed by Faff $(2015 ; 2019)$ to an academic project, i.e., "impact of digital mobile advertising on customers' purchase intention mediating role of customer motivation and customer perception". I started my research journey in 2015 during my MBA program. At that time, I was working on mobile learning in higher education institutions. My research supervisor introduced the concept of research pitch and advised me to work on pitching research letter (PRL). That was my first

1 Corresponding author: Department of Marketing, Griffith Business School, Griffith University, 1 - Parklands drive, Southport, QLD, 4215. Email: haroon.maseeh @ griffithuni.edu.au 
ever research project and I was not fully aware about the hardships of research journey. However, my supervisor helped me to be familiar with academic research process. I was advised that every research project has two challenges, i.e., starting and finishing (Faff, 2015). My supervisor advised me to get help from Professor Robert Faff's published work (Faff, 2015; Faff et al., 2017) which proved helpful; as a result, I finished my work in an efficient manner.

My first research pitch, titled Impact of behavioural factors towards the adoption of mobile learning among higher education students in public and private universities: A pitch (Iqbal \& Ashraf, 2017) was completed on $10^{\text {th }}$ July 2016. After finishing my PRL, I submitted that PRL to Journal of Accounting and Management Information Systems (JAMIS) for publication on $4^{\text {th }}$ October 2016. The first draft of my PRL could not be considered for publication. The anonymous reviewer provided with their expert feedback to polish that PRL which was reviewed for five times. During this process, the honourable editor, and the reviewer, both guided me to improve the pitching research letter. I am grateful to the editor Prof. Nadia Albu and the anonymous reviewer, and warmly acknowledge their kind efforts and cooperation. That PRL was published in the vol. 16 no. 3 of JAMIS on $3^{\text {rd }}$ October 2017. Even though this was a harsh journey, I got a good experience and enjoyed the process of applying the PRL template developed by Faff $(2015 ; 2019)$. Therefore, I decided to apply the same PRL template to my current academic project. I started working on this research pitch exercise on $14^{\text {th }}$ July 2019 and completed $2^{\text {nd }}$ Aug 2019.

The remaining part of this PRL is structured as follows. A brief summary on the completed pitch has been discussed in the next section. The third section comprises of my personal reflection on pitching exercise. Finally, this PRL ends with the conclusion section.

\section{Brief commentary on the pitching exercise}

My completed pitch titled "Impact of digital mobile advertising on customers' purchase intention; mediating role of customer motivation and customer perception" has been presented in Table 1 (Item A). The primary research question is what is the impact of digital mobile advertising on customers' purchase intention? (Item B). The key research papers (KPs) related to my research question are Martins et al. (2019), Dehghani and Tumer (2015), and Bart, Stephen, and Sarvary (2014) (Item C). Selection of the key research papers fulfil the criteria suggested by Faff et al. (2017):

1) Recently published;

2) Top-tier journals; and

3) By the experts in the fields. 
The first key research paper Martins et al. (2019) titled "How smartphone advertising influences consumers" purchase intention" examines the impact of various factors that motivate, and influence customers' purchase decision. This paper has been published in "Journal of Business Research" which is a highly reputed journal and categorised as "A" by Australian Business Deans Council $(\mathrm{ABDC})$.

The second key research paper Dehghani and Tumer (2015) investigates the Effectiveness of Facebook advertising on enhancing purchase intention of consumers. This research paper has been published in "Computers in Human Behavior", a well reputed journal published by Elsevier. This journal is ranked "B" in ABDC quality journal list. This study concludes that Facebook advertising has a significant positive impact on customers' purchase intention (Dehghani \& Tumer, 2015). The third key research paper titled Which Products Are Best Suited to Mobile Advertising? A Field Study of Mobile Display Advertising Effects on Consumer Attitudes and Intentions is published in the "Journal of Marketing Research", categorised as "A*" by ABDC. In this paper, researchers have examined the effectiveness of mobile advertisements and considered various products (Bart et al., 2014).

My research will unearth the effectiveness of smartphone advertising and introduce two mediating variables. It will contribute to the literature on mobile marketing. Furthermore, it will help understand customers' purchase intentions regarding products advertised through mobile media. 
Table 1. Completed research pitch template on Impact of Digital Mobile Advertising on Customers' Purchase Intention; Mediating Role of Customer Motivation and Customer Perception

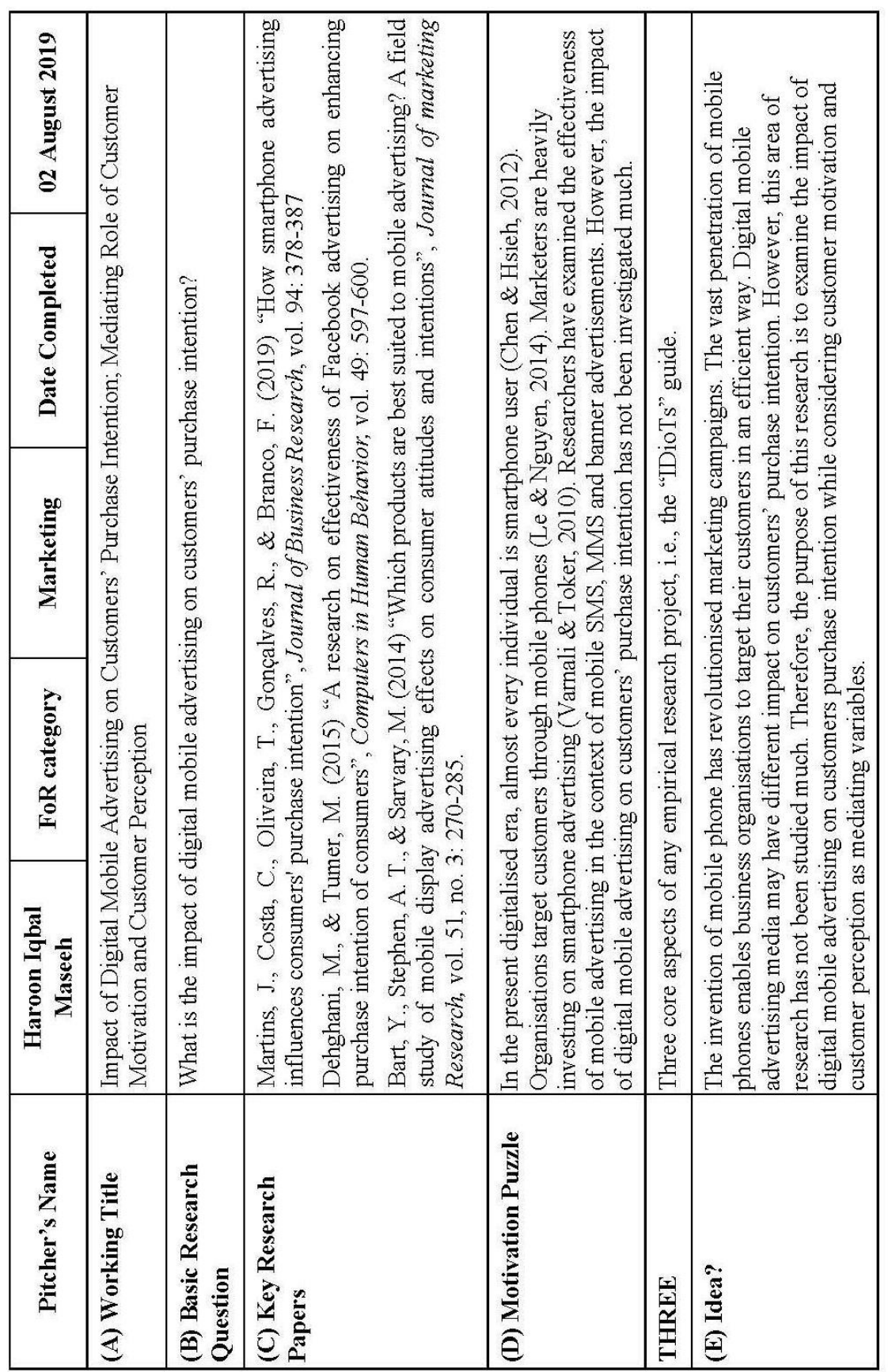




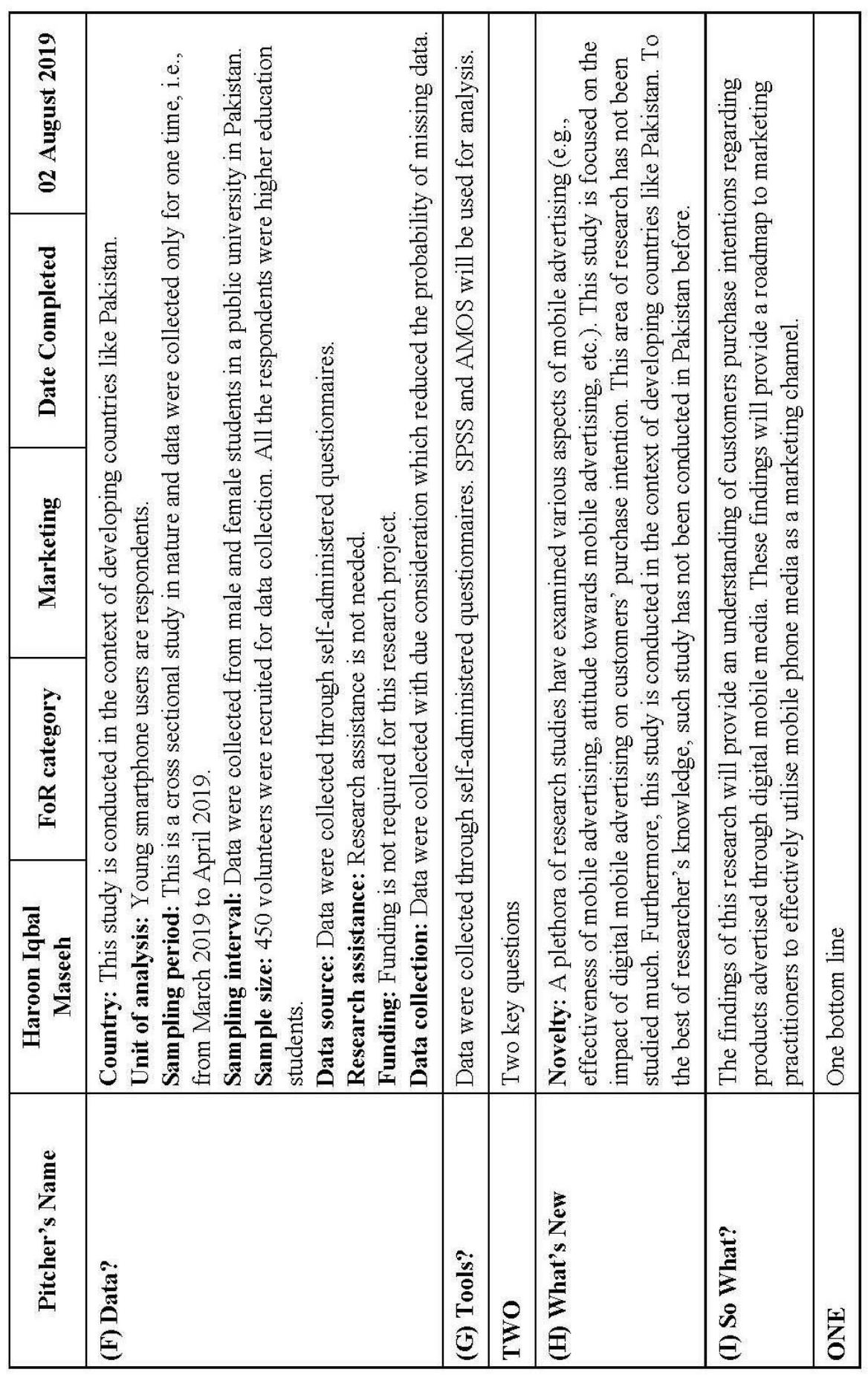




\begin{tabular}{|c|c|c|}
\hline 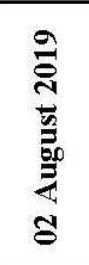 & 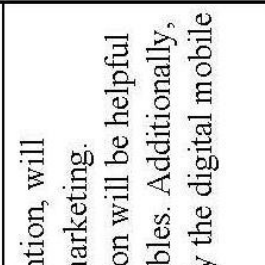 & 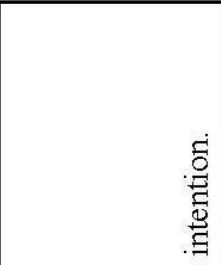 \\
\hline 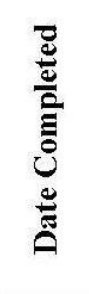 & 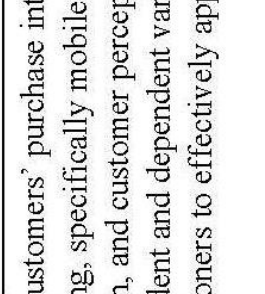 & 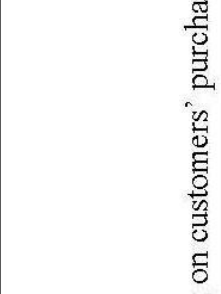 \\
\hline 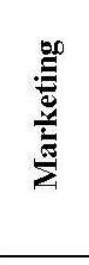 & 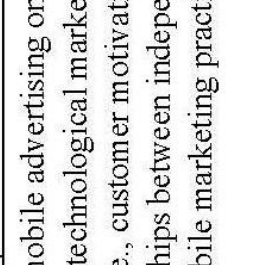 & 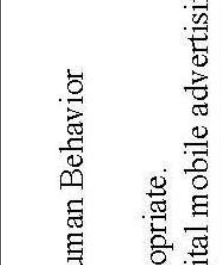 \\
\hline 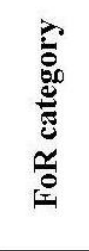 & 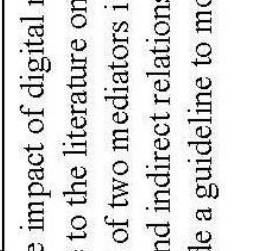 & 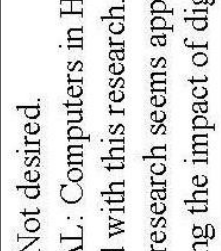 \\
\hline 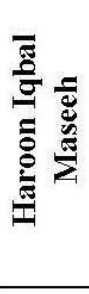 & 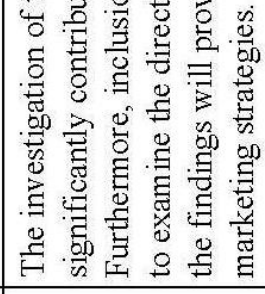 & 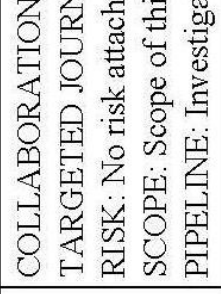 \\
\hline 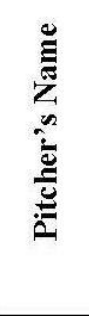 & 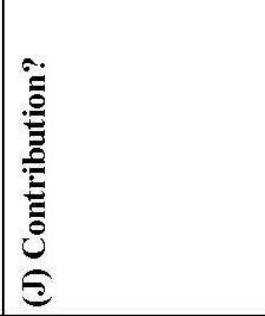 & 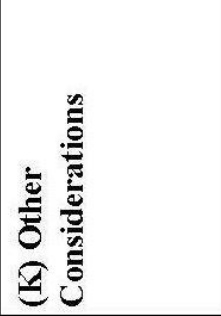 \\
\hline
\end{tabular}

Vol. 18, No. 4 


\section{Personal reflection on the pitch exercise}

The biggest challenge in every research project is to "start" and to start well (Faff, 2015). I completely agree with this statement. The reason is that how a researcher can determine that the area which is to be studied in the research is novel and will contribute to knowledge and practice? This cannot be identified until a researcher spends much time to review the existing literature around the area of study.

I found pitching exercise quite useful in my first research project (Iqbal \& Ashraf, 2017). This exercise helped me plan my overall research even when I was new in academic research. PRL exercise guided me in aligning my research project and enabled me to finish the research efficiently and effectively.

With the help of Mickey Mouse diagram, researchers can demonstrate their overall research plan and its outcomes in a simple and easily understandable manner. I used Mickey Mouse diagram in my first pitch exercise to present the scope of my research. I am doing the same practice on my current research project. Figure 1 demonstrates the Mickey Mouse diagram characterizing the novelty of research idea.

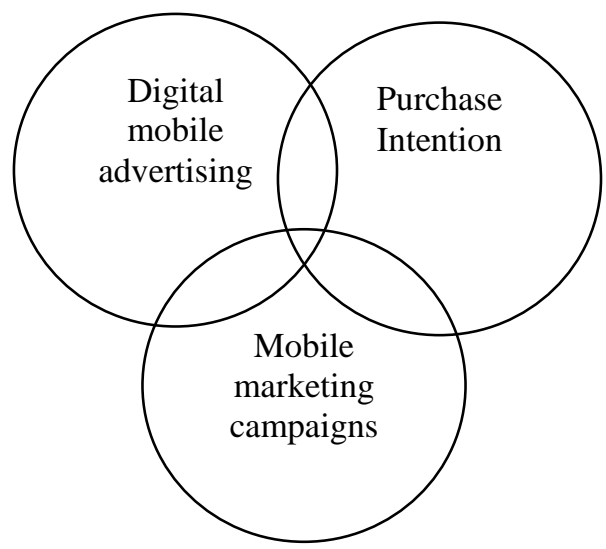

Figure 1: Mickey Mouse diagram characterizing novelty of research idea

\section{Conclusion}

Based on the PRL template proposed by Faff, $(2015 ; 2019)$, this PRL applies the pitching exercise on an academic project titled "Impact of digital mobile advertising on customers' purchase intention; mediating role of customer motivation and customer perception". This is the second time I am practicing PRL exercise. I personally find it useful for novice and early career researchers. Academics are highly busy persons and have no time to read every single page of 
research proposal. Pitching research approach helps researcher(s) present rich and detailed information regarding their research project in a compact, systematic, and efficient way (Macheka \& Kubíčeka, 2019).

\section{References}

Bart, Y., Stephen, A. T., \& Sarvary, M. (2014) "Which products are best suited to mobile advertising? A field study of mobile display advertising effects on consumer attitudes and intentions", Journal of Marketing Research, vol. 51, no.3: 270-285

Chen, P.-T., \& Hsieh, H.-P. (2012) "Personalized mobile advertising: Its key attributes, trends, and social impact", Technological Forecasting and Social Change, vol. 79, no.3: 543-557

Dehghani, M., \& Tumer, M. (2015) "A research on effectiveness of Facebook advertising on enhancing purchase intention of consumers", Computers in Human Behavior, vol. 49: 597-600

Faff, R.W. (2015) “A simple template for pitching research", Accounting \& Finance, vol. 55, no. 2: 311-336.

Faff, R.W. (2019) "Pitching Research", Available at SSRN: http://ssrn.com/abstract=2462059

Faff, R. W., Ali, S., Atif, M., Brenner, M., Chowdhury, H., Cruddas, L., . . Nagar, V. (2017) "Fantasy pitching", Available at SSRN 2782778.

Iqbal, H., \& Ashraf, H. A. (2017) "Impact of behavioral factors towards the adoption of mobile learning among higher education students in public and private universities: A pitch", Accounting and Management Information Systems, vol. 16, no. 3: 406-412

Le, T. D., \& Nguyen, B.-T. H. (2014) "Attitudes toward mobile advertising: A study of mobile web display and mobile app display advertising", Asian Academy of Management Journal, vol. 19, no. 2: 87

Macheka, O., \& Kubíčeka, A. (2019) "Socioemotional wealth in gay-owned family businesses: A pitch", Accounting and Management Information Systems, vol. 18 , no. 3: 443-449

Martins, J., Costa, C., Oliveira, T., Gonçalves, R., \& Branco, F. (2019) "How smartphone advertising influences consumers' purchase intention", Journal of Business Research, vol. 94: 378-387

Varnali, K., \& Toker, A. (2010) "Mobile marketing research: The-state-of-the-art", International journal of information management, vol. 30, no. 2: 144-151 